\title{
Addition of Wollastonite Fibers to Calcium Phosphate Cement Increases Cell Viability and Stimulates Differentiation of Osteoblast-Like Cells
}

\author{
Juliana Almeida Domingues, ${ }^{1,2}$ Mariana Motisuke, ${ }^{3}$ Celso Aparecido Bertran, ${ }^{4}$ \\ Moema A. Hausen, ${ }^{2}$ Eliana Aparecida de Rezende Duek, ${ }^{2,5}$ and José Angelo Camillii ${ }^{1}$ \\ ${ }^{1}$ Department of Structural and Functional Biology, Biology Institute, University of Campinas (UNICAMP), Campinas, SP, Brazil \\ ${ }^{2}$ Department of Physiological Science, Biomaterials Laboratory, Pontifical Catholic University of Sao Paulo (PUC-SP), \\ Sorocaba, SP, Brazil \\ ${ }^{3}$ Bioceramics Laboratory, Science and Technology Institute, Federal University of São Paulo (UNIFESP), \\ São José dos Campos, SP, Brazil \\ ${ }^{4}$ Department of Physical Chemistry, Chemistry Institute, University of Campinas (UNICAMP), Campinas, SP, Brazil \\ ${ }^{5}$ Department of Materials Engineering, Faculty of Mechanical Engineering, University of Campinas (UNICAMP), Campinas, SP, Brazil
}

Correspondence should be addressed to Juliana Almeida Domingues; almeidajad_bio@hotmail.com

Received 21 March 2017; Revised 7 July 2017; Accepted 19 July 2017; Published 21 August 2017

Academic Editor: Silvia Scaglione

Copyright ( 2017 Juliana Almeida Domingues et al. This is an open access article distributed under the Creative Commons Attribution License, which permits unrestricted use, distribution, and reproduction in any medium, provided the original work is properly cited.

\begin{abstract}
Calcium phosphate cement (CPC) that is based on $\alpha$-tricalcium phosphate ( $\alpha$-TCP) is considered desirable for bone tissue engineering because of its relatively rapid degradation properties. However, such cement is relatively weak, restricting its use to areas of low mechanical stress. Wollastonite fibers (WF) have been used to improve the mechanical strength of biomaterials. However, the biological properties of WF remain poorly understood. Here, we tested the response of osteoblast-like cells to being cultured on CPC reinforced with 5\% of WF (CPC-WF). We found that both types of cement studied achieved an ion balance for calcium and phosphate after 3 days of immersion in culture medium and this allowed subsequent long-term cell culture. CPC-WF increased cell viability and stimulated cell differentiation, compared to nonreinforced CPC. We hypothesize that late silicon release by CPC-WF induces increased cell proliferation and differentiation. Based on our findings, we propose that CPC-WF is a promising material for bone tissue engineering applications.
\end{abstract}

\section{Introduction}

Calcium phosphate cement (CPC) possesses excellent biocompatibility and osteoconductivity in vivo and is commonly used as a biomaterial in bone implants [1]. CPC is made of calcium phosphates, such as $\alpha$-tricalcium phosphate $(\alpha$ TCP) or $\beta$-tricalcium phosphate $(\beta$-TCP), which in contact with water dissolves and precipitates into calcium deficient hydroxyapatite $[2,3]$. The resulting degradation products of $\mathrm{CPC}$, such as calcium and phosphorus, induce the bioactivity of the material $[3,4]$, although the poor mechanical properties restrict its applications to small oral maxillofacial defects and the covering of metallic prostheses $[5,6]$.
In trials aimed at improving the mechanical properties of CPC, small and elongated fibers and whiskers have been applied as a reinforcing material [7]. The reinforcement would be made of calcium phosphate compounds (hydroxyapatite whiskers and fibers) [8], calcium carbonates (aragonite whiskers) [9], and calcium silicates $\left(\mathrm{CaSiO}_{3}\right.$, wollastonite whiskers, and fibers [WF]) [10]. Recent studies suggest that the addition of inorganic silicon compounds to biomaterials such as hydroxyapatite and bioactive glasses might influence the metabolism of osteoblast-like cells involved in the process of mineralization [11, 12]. Also, solutions containing a high concentration of inorganic silicon compounds stimulate the 
expression of genes related to bone activity, enabling bone neoformation by osteoblast-like cells [13].

The mechanical properties of $\alpha$-TCP-based CPC can be enhanced by the addition of $\mathrm{WF}\left(\mathrm{CaSiO}_{3}\right)$ [14]. This raises the possibility of increasing the bioactivity of CPC through the release of silicon during wollastonite hydrolysis. Motisuke et al. [14] found that addition of 5\% (w/w) WF reinforces the compressive strength of an apatite CPC by $250 \%$ compared to nonreinforced CPC (from 14.5 to $50.4 \mathrm{MPa}$ ). Wollastonite exhibits excellent in vitro bioactivity [15], as demonstrated by the relatively rapid formation of an apatite layer on its surface compared to other bioactive materials (e.g., bioactive glass). Formation of this apatite layer is essential for integration of the implanted material to the surrounding bone, favoring the proliferation and activity of osteoblast-like cells [16].

The purpose of the present study was to compare the cytocompatibility of CPC and CPC-WF in vitro. The study evaluated the potential of the two types of cement as a substrate for the differentiation, adhesion, and proliferation of osteoblast-like cells.

\section{Material and Methods}

2.1. Material. $\alpha$-TCP was obtained by solid-state reaction as published elsewhere [17]. Briefly, a stoichiometric mixture of $\mathrm{Mg}$-free calcium carbonate $\left(\mathrm{CaCO}_{3}\right)$ and $\mathrm{Mg}$-free monetite $\left(\mathrm{CaHPO}_{4}\right)$ was calcined at $1300^{\circ} \mathrm{C}$ and milled to achieve a granulometric distribution of 1.33 to $10 \mu \mathrm{m}$ and a mean particle size of $4.93 \mu \mathrm{m}$. WF were synthesized by the salt fusion method [14]. In summary, calcium carbonate $\left(\mathrm{CaCO}_{3}\right.$, Sigma Aldrich) and electronic grade silicon dioxide (fumed $\mathrm{SiO}_{2}$, Sigma Aldrich) were intimately mixed with a $\mathrm{NaCl} / \mathrm{KCl}$ flux and calcined at $950^{\circ} \mathrm{C}$ and salt was washed out with deionized water. To prepare CPC-WF, $\alpha$-TCP and WF were mixed at a $\alpha$ TCP to WF ratio of $5 \%(\mathrm{w} / \mathrm{w})$. This $5 \% \mathrm{WF}$ ratio was assumed optimal for increasing the mechanical properties of CPC, as shown in our previous work [14]. CPC composite disks (WF reinforced $[\mathrm{CPC}-\mathrm{WF}]$ and nonreinforced $[\mathrm{CPC}]$ ) were autoclaved and immersed in sterile culture medium. All disks were $0.8 \mathrm{~mm}$ in diameter. Before cell seeding, all CPC and CPC-WF disks were immersed in Dulbecco's modified Eagle's medium (DMEM) for 3 days, with medium replaced daily. This was to achieve ion balance with the culture medium. The daily medium change was necessary to stabilize the balance of essential ions, as previously reported [18].

2.2. Isolation of Osteoblast-Like Cells. Osteoblast-like cells were obtained from the calvaria of 20-day-old Lewis rats by the explant method. This experimental protocol was approved by the Ethics Committee on Animal Use of UNICAMP (CEUA 2606-01). Before each cell isolation procedure, animals were sacrificed, and the calvaria is removed and immersed in DMEM (Sigma Aldrich, catalog number D5796) supplemented with antibiotics (Sigma Aldrich, catalog number A5955). The soft tissue was removed with a scalpel. Next, the calvaria was fragmented and immersed in flasks containing DMEM supplemented with antibiotics and 10\% fetal bovine serum (Sigma Aldrich, catalog number 2442). The culture flasks were kept at $37^{\circ} \mathrm{C}$ in a $5 \% \mathrm{CO}_{2}$ atmosphere.
The medium was changed every 2-3 days and cells were used for the experiments until the fourth passage.

2.3. Cell Viability. Cell viability was evaluated after 1,7 , and 14 days in culture. After the ion balance period (described above), cells were seeded on the materials at a concentration of $3 \times 10^{4}$ cells per disk. As negative controls, cells were cultured in a polystyrene 24-well plate. After incubation, viable cells were evaluated using a colorimetric MTT (3-(4,5-dimethylthiazol-2-yl)-2,5-diphenyl tetrazolium bromide) (Sigma Aldrich, catalog number 88417) reduction assay for mitochondrial activity (Sigma Aldrich, USA). After $4 \mathrm{~h}$ of incubation in the presence of MTT, absorbance readings were made using a microplate reader (model Elx-800UV, Bio-Tek Instruments, USA) at a wavelength of $570 \mathrm{~nm}$.

2.4. Scanning Electron Microscopy. Cell morphology on CPC disks was analyzed by scanning electron microscopy (JEOL JXA-840A). For this purpose, samples were fixed in a solution of $4 \%$ paraformaldehyde (Prolab, catalog number 01P1005.01.A), 2.5\% glutaraldehyde (Millipore, catalog number 104239), 0.03\% picric acid (VETEC QUÍMICA FINA LTDA, catalog number 000910.06), and 1\% tannic acid (Synth, catalog number 01A2012.01.AF) in DMEM for $30 \mathrm{~min}$. Next, samples were washed in Phosphate Buffer Saline (PBS), postfixed in 1\% osmium tetroxide (Sigma Aldrich, catalog number, 419494), and dehydrated in an increasing ethanol series. Samples were then critical-point dried (Balzers CTD 030) and sputtered with gold (Balzers SCD 050).

2.5. Alkaline Phosphatase. Alkaline phosphatase (ALP) activity was assayed to identify the early stage of osteoblast differentiation in the various materials. ALP activity can indicate whether cells are osteoblast-like cells. The colorimetric method used was based on the conversion of p-nitrophenyl phosphate into p-nitrophenol in the presence of ALP. Cells were seeded on disks with DMEM supplemented with $3 \mathrm{mM}$ $\beta$-glycerol phosphate, $0.1 \mathrm{mM}$ ascorbic acid, and $1 \mathrm{nM}$ dexamethasone. ALP activity was measured at 7, 10, and 14 days after incubation. Before the assay, disks were washed twice with PBS and cells were lysed by sonication and Triton X100 , according to the manufacturer's instructions (SensoLyte ${ }^{\circledR}$ pNPP Alkaline Phosphatase Assay Kit, Anaspec, Inc.). Production of p-nitrophenol was measured by absorbance in a microplate reader (model Elx-800-UV, Bio-Tek Instruments, USA) at a wavelength of $405 \mathrm{~nm}$.

2.6. Inductively Coupled Plasma Optical Emission Spectroscopy (ICP-OES). To determine $\mathrm{Ca}^{2+}, \mathrm{Si}$, and $\mathrm{P}$ ion levels, aliquots of medium were removed during the ion balance period (during days 1 and 3 of culture) and during cell culture (at days 1,7 , and 14) and analyzed by ICP-OES (Perkin Elmer, Optima 3000DV).

2.7. Statistical Analysis. All data were compared by one-way analysis of variance (ANOVA). Whenever statistically significant differences $(p<0.05)$ were identified, Tukey's post hoc test was applied (BioEstat, version 5.0). All experiments were performed in quintuplicate. 


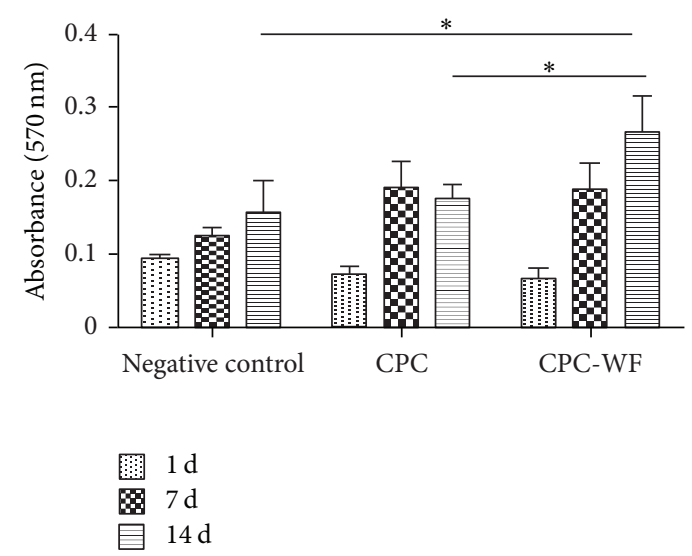

FIGURE 1: MTT assays after 1, 7, and 14 days of cell culture on CPC disks. Data are expressed as means and standard deviation. $p$ values of $<0.01$ are indicated by an asterisk.

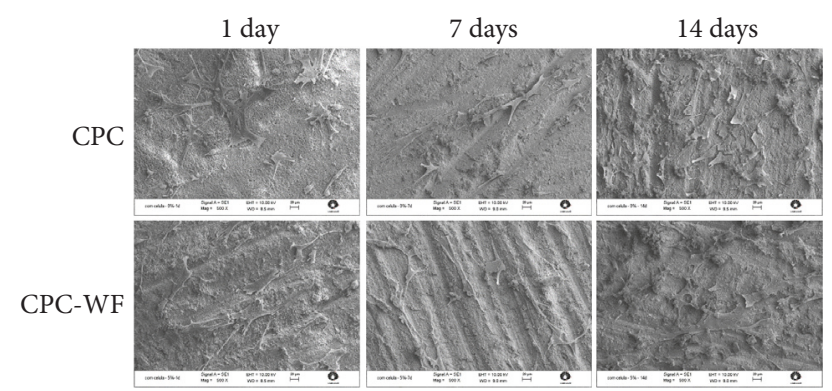

FIGURE 2: Scanning electron micrographs of CPC and CPC-WF disks after 1, 7, and 14 days of culture. Osteoblast-like cells were well adhered, and the topography of the material did not interfere with cell adhesion.

\section{Results}

3.1. Cell Viability. In all samples tested, the cell viability assay showed increased cell metabolic activity over time. However, significantly higher cell activity $(p<0.01)$ was observed on CPC-WF than on either polystyrene plates (negative control) or CPC (Figure 1).

3.2. Cell Morphology. Scanning electron microscopy showed that cells were able to adhere and spread on the tested samples (Figure 2). Cytoplasmic prolongations were observed in all samples after 1,7 , and 14 days of culture.

3.3. Alkaline Phosphatase Activity. ALP activity increased over time in all samples and was significantly higher in CPCWF samples than CPC samples after 14 days of cell culture $(p<0.05)$ (Figure 3).

3.4. Concentration of $\mathrm{Ca}^{2+}, \mathrm{Si}$, and P Ions in Culture Medium. During the ion balance period, we noted a depletion of $\mathrm{Ca}^{2+}$ and release of $\mathrm{P}$ ions after 1 day of immersion in DMEM. On day 3 of the ion balance period, we detected an increase in $\mathrm{Ca}^{2+}$ concentration and reduction in the release of $\mathrm{P}$ ions. ICP-OES data indicated that the $\mathrm{Ca}^{2+}$ and $\mathrm{P}$ concentrations

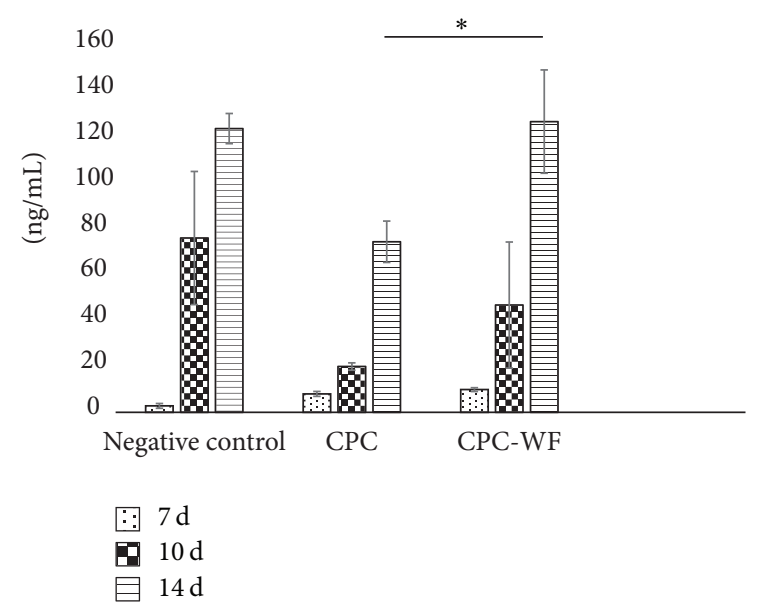

FIgUre 3: Alkaline phosphatase activity after 7, 10, and 14 days of culture. Negative control represents cells induced to differentiate and cultured in the well plate. $p$ values of $<0.01$ are indicated by an asterisk.

in CPC and CPC-WF samples were similar to those of the negative control after 3 days of ion balance in DMEM. There was a steady decrease in the rate of Si release from CPCWF samples throughout the immersion period (Figure 4). All of the evaluated ions $\left(\mathrm{Ca}^{2+}, \mathrm{Si}\right.$, and $\left.\mathrm{P}\right)$ were at similar concentrations after 7 and 14 days of culture. These data suggest that ion levels become balanced by day 7 of culture (Figure 4). For this reason, we omitted the day 14 data from Figure 4.

\section{Discussion}

In vitro analysis of biomaterials in cell culture is a valuable tool for understanding how recently developed materials elicit adverse reactions at the cellular level $[15,16]$. Suitable biomaterials should be noncytotoxic and be able to maintain and stimulate cell differentiation [19]. Here, we evaluated the response of cultured osteoblast-like cells to WF-reinforced CPC.

We found that both CPC and CPC-WF enable cell adhesion, spreading, and increased viability over time. However, after 14 days in culture, cell viability was significantly higher on CPC-WF than CPC. Cell adhesion and proliferation depend on both the physical and chemical characteristics of their substrate [20]. CPC undergoes hydrolysis while in contact with aqueous solution, giving rise to a layer of apatite that resembles biological apatite. Such layer is a common characteristic of bioactive materials and enables binding to bone tissue, thus improving graft assimilation [21]. According to Chou et al. [16], this process is essential for the formation, growth, and maintenance of a tissue-biomaterial interface, as well as for proliferation and bone matrix synthesis. MorejónAlonso et al. [22] demonstrated that addition of calcium silicate to a $\alpha$-TCP-based cement improves bioactivity by hastening the formation of a dense apatite layer over the cement surface. Based on our data, together with the work of Morejón-Alonso et al. [22], we propose that hastened apatite layer formation could account for the increased cell viability of CPC-WF compared to CPC observed here. 

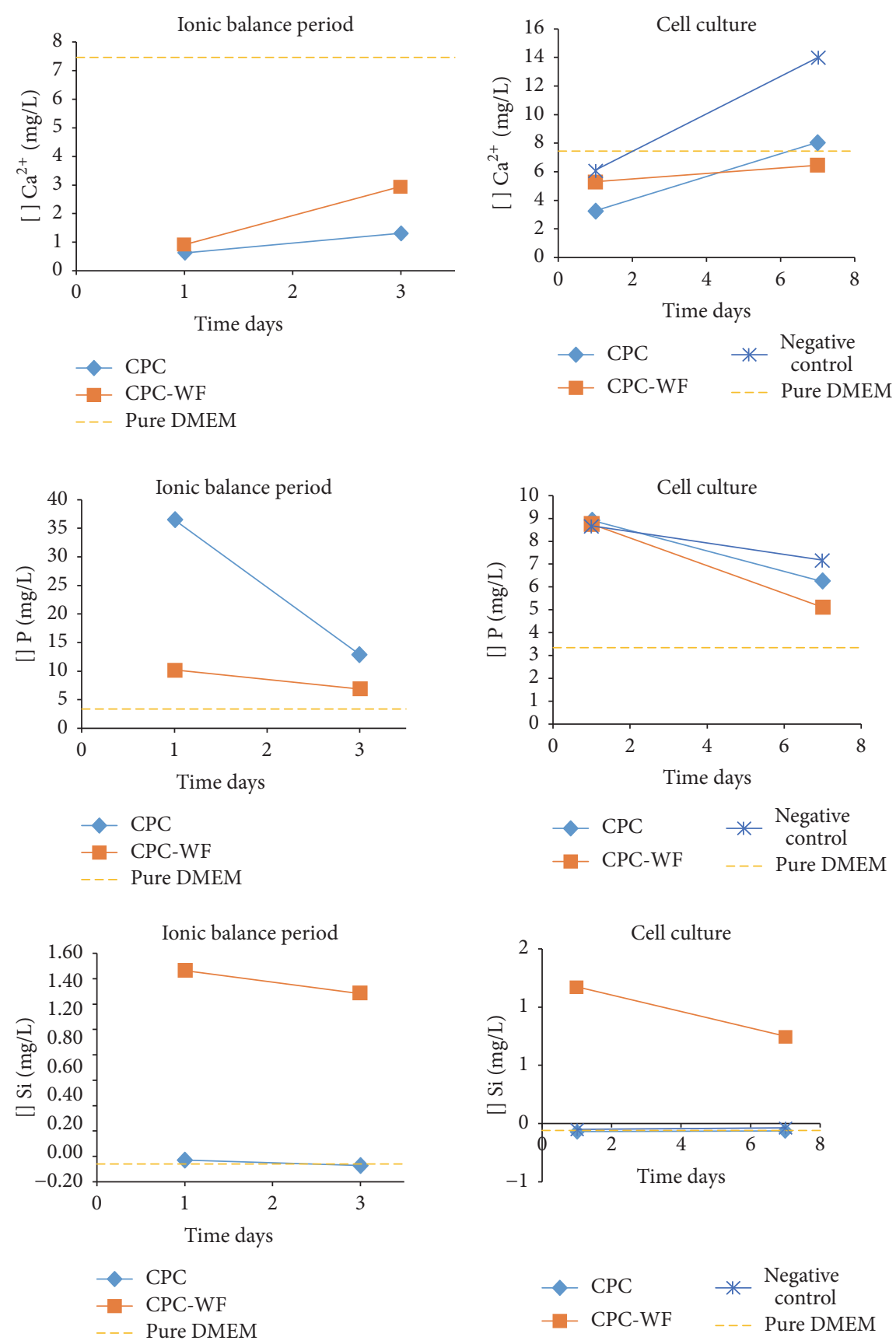

FIGURE 4: $\mathrm{Ca}^{2+}, \mathrm{Si}$, and $\mathrm{P}$ ion concentrations in culture medium during the 3-day ionic balance period (quantifications at days 1 and 3 ) and under cell culture (days 1 and 7). DMEM alone was used as a control.

In addition to the physical characteristics of $\mathrm{CPC}$, which favor cell adhesion and proliferation, the chemical composition of cement also influences cellular responses. Mestres et al. [18] studied the ionic properties of CPC doped with silicon in culture medium and the influence of these ions on the response of osteoblast-like cells and observed calcium depletion in medium containing CPC. These authors also reported a delay in cell proliferation that was attributed to the material's strong ionic modification. Unlike Mestres et al. [18], we observed an increase in cell viability over time in both types of cement studied after the ionic balance period. In addition, as compared to CPC, the cell viability in CPC-WF was significantly increased. Other studies reported similar results about the role of silicon in osteoblast-like cell proliferation $[11,23]$. Cell death after culture in calcium phosphates has been reported [24-26], which is generally attributed to changes in the ion concentration of the medium. According to Tamai et al. [27], the release of $\mathrm{P}$ from calcium phosphatebased materials induced the formation of phosphoric acids, leading to acidification of the culture medium. We also demonstrated that $\mathrm{P}$ release alters the $\mathrm{pH}$ of the medium, which changes from its usual red to a yellow appearance. 
Here, after the second medium change of the ion balance period, the culture medium $\mathrm{pH}$ remained stable (neutral). ICP-OES analyses found that, on day 3 of the ion balance period, there is a reduction in the release of $\mathrm{P}$ into the culture medium in the presence of CPC. Thus, we propose that the ion balance period used here facilitated an increase in cell viability during subsequent cell culture steps.

The ability to induce differentiation of osteoblast-like cells is fundamental to the success of biomaterials for bone tissue engineering. ALP is known to be an early marker of osteoblast differentiation [28]. This enzyme hydrolyzes phosphate substrates and results in the release of inorganic phosphate, which binds to calcium and forms hydroxyapatite [29]. Peak ALP activity generally corresponds to the onset of mineralization [30]. Our data demonstrate a direct link between the addition of WF in CPC and the production of ALP. The biological role of $\mathrm{Si}$ in bone metabolism is still unclear; several studies have shown that the presence of silicon in biomaterials stimulates bone formation [20,31,32] and enhanced ALP activity and expression $[33,34]$.

\section{Conclusion}

Taken together, our data suggest that CPC samples are likely to achieve ion balance with their culture medium over time. Only after this balance has been achieved, can cells be cultured and maintained for long periods. All types of CPC tested here were biocompatible for osteoblast-like cells. The addition of WF increased cell viability, as well as the activity of ALP, which could be directly related to silicon release in the medium. Our findings suggest that CPC-WF could be applied as a scaffold in bone tissue engineering strategies.

\section{Abbreviations}

\begin{tabular}{|c|c|}
\hline ALP: & Alkaline phosphatase \\
\hline CPC: & Calcium phosphate cement \\
\hline DMEM: & Dulbecco's modified Eagle's medium \\
\hline ICP-OES: & $\begin{array}{l}\text { Inductively coupled plasma optical } \\
\text { emission spectroscopy }\end{array}$ \\
\hline MTT: & $\begin{array}{l}\text { 3-(4,5-Dimethylthiazol-2-yl)-2,5-diphenyl } \\
\text { tetrazolium bromide }\end{array}$ \\
\hline PBS: & Phosphate buffer saline \\
\hline WF: & Wollastonite fibers \\
\hline$\alpha$-TCP: & $\alpha$-Tricalcium phosphate. \\
\hline
\end{tabular}

\section{Conflicts of Interest}

No potential conflicts of interest were disclosed.

\section{References}

[1] M. Kamitakahara, C. Ohtsuki, and T. Miyazaki, "Review paper: behavior of ceramic biomaterials derived from tricalcium phosphate in physiological condition," Journal of Biomaterials Applications, vol. 23, no. 3, pp. 197-212, 2008.

[2] R. G. Carrodeguas and S. De Aza, " $\alpha$-Tricalcium phosphate: synthesis, properties and biomedical applications," Acta Biomaterialia, vol. 7, no. 10, pp. 3536-3546, 2011.
[3] M. Motisuke, G. Mestres, C. O. Renó, R. G. Carrodeguas, C. A. Zavaglia, and M. Ginebra, "Influence of Si substitution on the reactivity of $\alpha$-tricalcium phosphate," Materials Science and Engineering: C, vol. 75, pp. 816-821, 2017.

[4] R. Z. LeGeros, "Properties of osteoconductive biomaterials: calcium phosphates," Clinical Orthopaedics and Related Research, no. 395, pp. 81-98, 2002.

[5] A. Boyde, A. Corsi, R. Quarto, R. Cancedda, and P. Bianco, "Osteoconduction in large macroporous hydroxyapatite ceramic implants: evidence for a complementary integration and disintegration mechanism," Bone, vol. 24, no. 6, pp. 579-589, 1999.

[6] S. V. Dorozhkin, "Calcium orthophosphate-based biocomposites and hybrid biomaterials," Journal of Materials Science, vol. 44, no. 9, pp. 2343-2387, 2009.

[7] R. Krüger and J. Groll, "Fiber reinforced calcium phosphate cements - on the way to degradable load bearing bone substitutes?" Biomaterials, vol. 33, no. 25, pp. 5887-5900, 2012.

[8] C. B. Carter and M. G. Norton, "Introduction," in Ceramic Materials, Springer, New York, NY, USA, 2013.

[9] J. Zhang, Y. Zhang, K. Xu, and V. Ji, "Young's modulus surface and poisson's ratio curve for orthorhombic crystals," Journal of Chemical Crystallography, vol. 38, no. 10, pp. 733-741, 2008.

[10] N. I. Demidenko and A. P. Stetsovskii, "Correlation between elastic properties of wollastonite-based materials and sintering temperature," Glass and Ceramics, vol. 60, no. 7-8, pp. 217-218, 2003.

[11] C. Botelho, R. Brooks, S. Best et al., "Human osteoblast response to silicon-substituted hydroxyapatite," Journal of Biomedical Materials Research Part A, vol. 79A, no. 3, pp. 723-730, 2006.

[12] A. E. Porter, "Nanoscale characterization of the interface between bone and hydroxyapatite implants and the effect of silicon on bone apposition," Micron, vol. 37, no. 8, pp. 681-688, 2006.

[13] G. Gupta, S. Kirakodu, and A. El-Ghannam, "Dissolution kinetics of a Si-rich nanocomposite and its effect on osteoblast gene expression," Journal of Biomedical Materials Research - Part A, vol. 80, no. 2, pp. 486-496, 2007.

[14] M. Motisuke, V. R. Santos, N. C. Bazanini, and C. A. Bertran, "Apatite bone cement reinforced with calcium silicate fibers," Journal of Materials Science: Materials in Medicine, vol. 25, no. 10, pp. 2357-2363, 2014.

[15] D. A. Cortés, A. Medina, J. C. Escobedo, S. Escobedo, and M. A. López, "Effect of wollastonite ceramics and bioactive glass on the formation of a bonelike apatite layer on a cobalt base alloy," Journal of Biomedical Materials Research Part A, vol. 70A, no. 2, pp. 341-346, 2004.

[16] Y.-F. Chou, W. Huang, J. C. Y. Dunn, T. A. Miller, and B. M. $\mathrm{Wu}$, "The effect of biomimetic apatite structure on osteoblast viability, proliferation, and gene expression," Biomaterials, vol. 26, no. 3, pp. 285-295, 2005.

[17] M. Motisuke, R. García Carrodeguas, and C. A. C. Zavaglia, "Mg-free precursors for the synthesis of pure phase Si-doped $\alpha-\mathrm{Ca}_{3}(\mathrm{PO} 4)_{2}$," Key Engineering Materials, pp. 199-202, 2008.

[18] G. Mestres, C. Le Van, and M.-P. Ginebra, "Silicon-stabilized $\alpha$-tricalcium phosphate and its use in a calcium phosphate cement: characterization and cell response," Acta Biomaterialia, vol. 8, no. 3, pp. 1169-1179, 2012.

[19] L. L. Hench and I. Thompson, "Twenty-first century challenges for biomaterials," Journal of the Royal Society Interface, vol. 7, no. 4, pp. S379-S391, 2010. 
[20] S. Ni, J. Chang, L. Chou, and W. Zhai, "Comparison of osteoblast-like cell responses to calcium silicate and tricalcium phosphate creamics in vitro," Journal of Biomedical Materials Research-Part B Applied Biomaterials, vol. 80, no. 1, pp. 174183, 2007.

[21] M. G. Gandolfi, G. Ciapetti, P. Taddei et al., "Apatite formation on bioactive calcium-silicate cements for dentistry affects surface topography and human marrow stromal cells proliferation," Dental Materials, vol. 26, no. 10, pp. 974-992, 2010.

[22] L. Morejón-Alonso, O. J. B. Ferreira, R. G. Carrodeguas, and L. A. Dos Santos, "Bioactive composite bone cement based on $\alpha$ tricalcium phosphate/tricalcium silicate," Journal of Biomedical Materials Research - Part B Applied Biomaterials, vol. 100, no. 1, pp. 94-102, 2012.

[23] M.-Y. Shie, S.-J. Ding, and H.-C. Chang, "The role of silicon in osteoblast-like cell proliferation and apoptosis," Acta Biomaterialia, vol. 7, no. 6, pp. 2604-2614, 2011.

[24] D. P. Link, J. van den Dolder, J. G. Wolke, and J. A. Jansen, "The cytocompatibility and early osteogenic characteristics of an injectable calcium phosphate cement," Tissue Engineering, vol. 13, pp. 493-500, 2006.

[25] A. John, H. K. Varma, and T. V. Kumari, "Surface reactivity of calcium phosphate based ceramics in a cell culture system," Journal of Biomaterials Applications, vol. 18, no. 1, pp. 63-78, 2003.

[26] U. Hempel, A. Reinstorf, M. Poppe et al., "Proliferation and differentiation of osteoblasts on Biocement D modified with collagen type I and citric acid," Journal of Biomedical Materials Research - Part B Applied Biomaterials, vol. 71, no. 1, pp. 130-143, 2004.

[27] M. Tamai, R. Nakaoka, and T. Tsuchiya, "Cytotoxicity of various calcium phosphate ceramics," Key Engineering Materials, vol. 309-311, pp. 263-266, 2006.

[28] H. Orimo, "The mechanism of mineralization and the role of alkaline phosphatase in health and disease," Journal of Nippon Medical School, vol. 77, no. 1, pp. 4-12, 2010.

[29] H. Orimo and T. Shimada, "The role of tissue-nonspecific alkaline phosphatase in the phosphate-induced activation of alkaline phosphatase and mineralization in SaOS-2 human osteoblast-like cells," Molecular and Cellular Biochemistry, vol. 315, no. 1-2, pp. 51-60, 2008.

[30] J. B. Lian and G. S. Stein, "Development of the osteoblast phenotype: molecular mechanisms mediating osteoblast growth and differentiation," The Iowa Orthopaedic Journal, vol. 15, pp. 118140, 1995.

[31] B.-S. Kim, S.-S. Yang, J.-H. Yoon, and J. Lee, "Enhanced bone regeneration by silicon-substituted hydroxyapatite derived from cuttlefish bone," Clinical Oral Implants Research, vol. 28, no. 1, pp. 49-56, 2017.

[32] I. Christodoulou, L. D. K. Buttery, P. Saravanapavan, G. Tai, L. L. Hench, and J. M. Polak, "Dose- and time-dependent effect of bioactive gel-glass ionic-dissolution products on human fetal osteoblast-specific gene expression," Journal of Biomedical Materials Research - Part B Applied Biomaterials, vol. 74, no. 1, pp. 529-537, 2005.

[33] S. Dong, J. Sun, Y. Li, J. Li, W. Cui, and B. Li, "Electrospun nanofibrous scaffolds of poly (l-lactic acid)-dicalcium silicate composite via ultrasonic-aging technique for bone regeneration," Materials Science and Engineering C, vol. 35, no. 1, pp. 426433, 2014.
[34] B.-C. Wu, C.-T. Kao, T.-H. Huang, C.-J. Hung, M.-Y. Shie, and H.-Y. Chung, "Effect of verapamil, a calcium channel blocker, on the odontogenic activity of human dental pulp cells cultured with silicate-based materials," Journal of Endodontics, vol. 40, no. 8, pp. 1105-1111, 2014. 

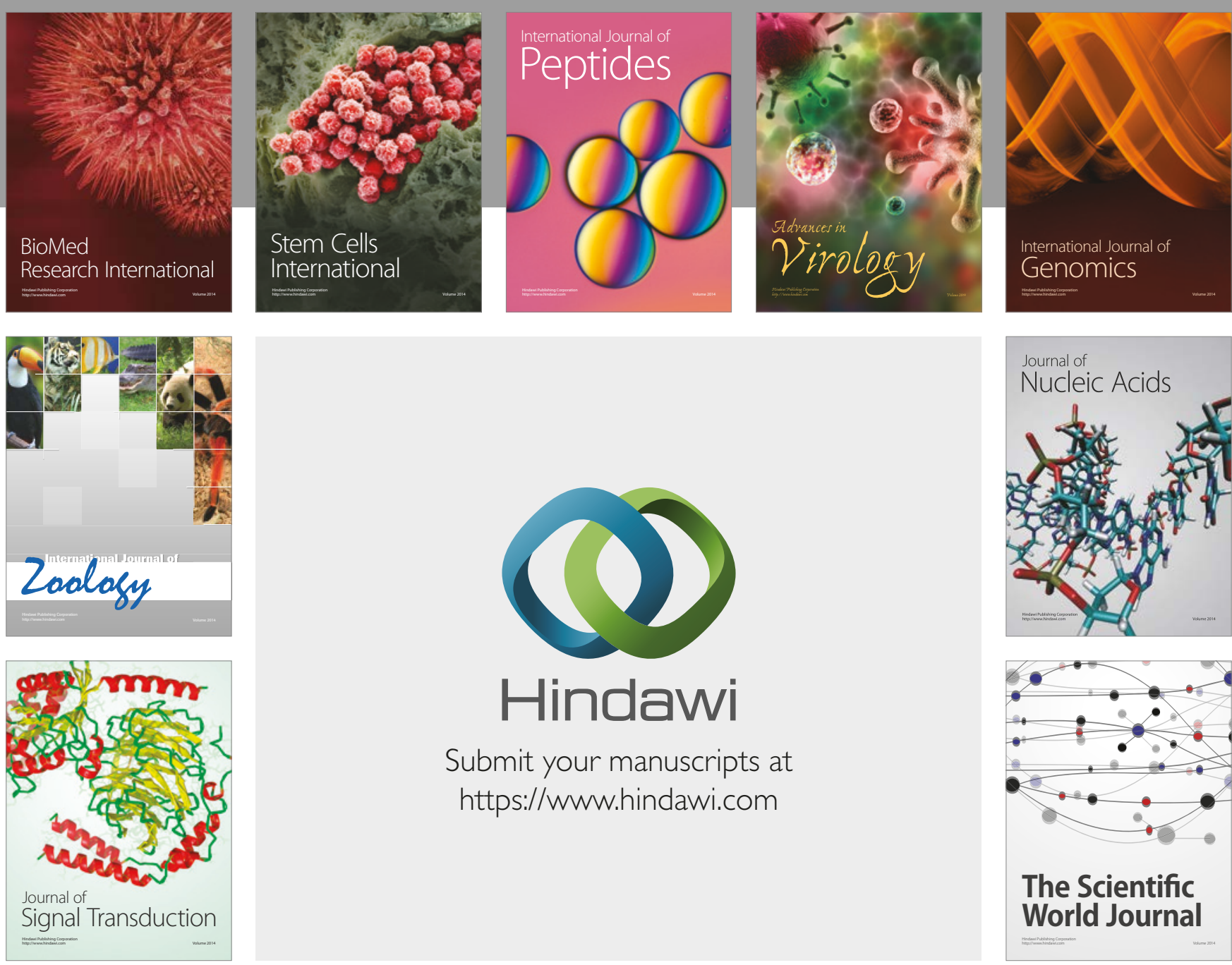

Submit your manuscripts at

https://www.hindawi.com
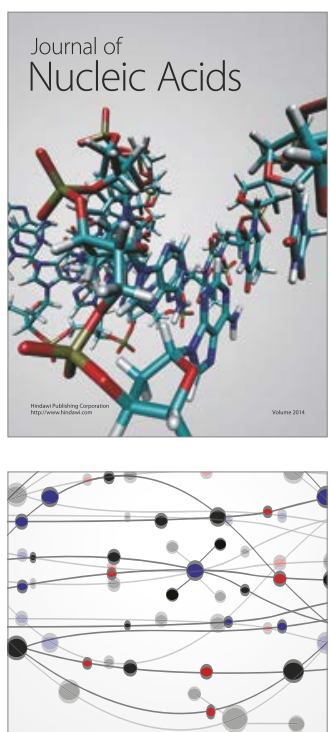

The Scientific World Journal

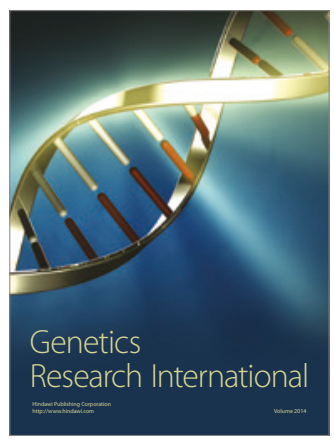

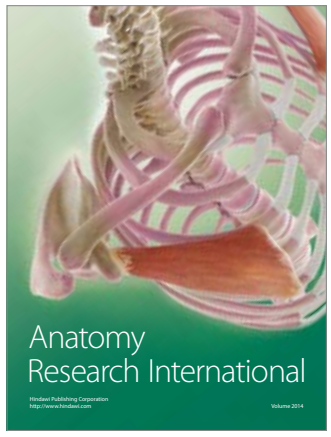

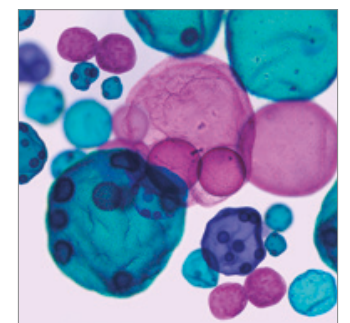

International Journal of Microbiology
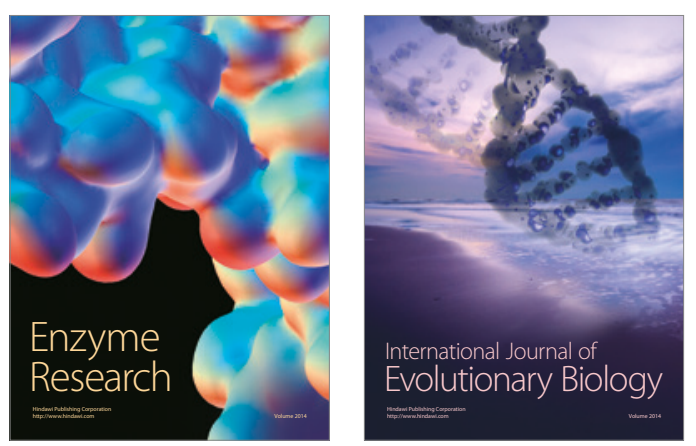
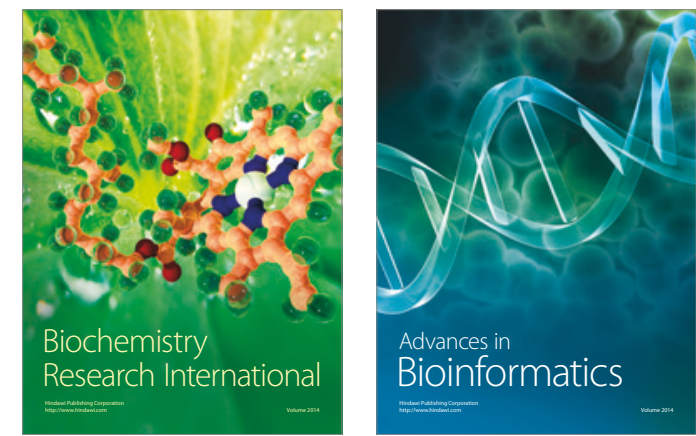

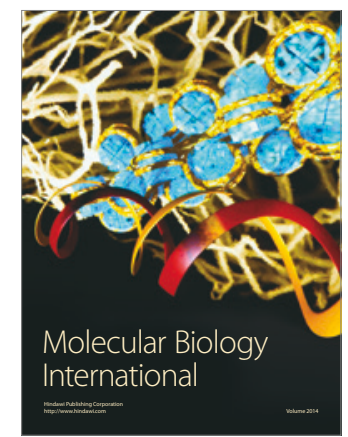

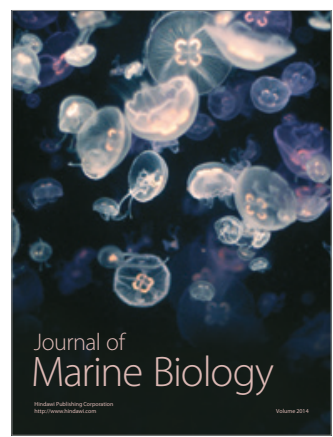

